\title{
ASSESSMENT OF PERSONALITY FACTORS AMONG PATIENTS PRESENTING WITH DIFFERENT SUBSTANCE USE DISORDERS
}

\author{
Bharti Poonam ${ }^{1}$, Bhatti Karun², Singh Harshbir Angad³, Walia Hemank ${ }^{4}$, Lal Dhruvendra5, Puri Shradha 6
}

1Associate Professor, Department of Psychiatry, MMIMSR, Mullana, Ambala, Haryana, India.

${ }^{2}$ Associate Professor, Department of Medicine, MMIMSR, Mullana, Ambala, Haryana, India.

3 Postgraduate Resident, Department of Psychiatry, MMIMSR, Mullana, Ambala, Haryana, India.

${ }_{4}^{4}$ MBBS Student, MMIMSR, Mullana, Ambala, Haryana, India.

${ }_{5}^{5}$ Senior Resident and Incharge, Department of Community Medicine, CMC\&H, Ludhiana, Punjab, India.

${ }^{6}$ Psychologist, Department of Psychiatry, MMIMSR, Mullana, Ambala, Haryana, India.

\section{BACKGROUND}

ABSTRACT

Substance use disorder is increasing day by day, as individuals are using substance for recreational purposes to get excitement out of its use. Extensive use of substance is causing significant damage to mental, physical, psychological and social health of an individual. Although the use of any substance is markedly influenced by an individual's own personality traits, we wanted to study the personality factors among the patients with different substance use disorders and associated factors.

\section{METHODS}

This hospital based, observational study was carried out to assess the various personality factors among 90 subjects using various substances (alcohol, opioids, cannabis, nicotine smoking, tobacco chewer, benzodiazepine abuser etc.). The sample was divided into three groups based on type of substance use disorder i.e., alcohol, opioids and others. Purposive sampling method was used for collecting data. Sixteen Personality Factor questionnaire and sociodemographic proforma was administered for assessing the personality, and getting basic data of the subjects.

\section{RESULTS}

A total of 90 subjects participated in this study. It was found that $33.33 \%$ of the subjects were using alcohol, $33.33 \%$ opioid s and $33.3 \%$ others (cannabis, nicotine smoking, tobacco chewer, benzodiazepine abuser). Range of duration of intake is also significantly associated with type of substance abuse. The range of duration was more in alcoholics and others than in opioids. Only self-discipline mean scores were significantly associated with the type of substance abuse participants were using.

\section{CONCLUSIONS}

Substance dependence will become a major issue, if not handled properly by the professional healers. It was observed that all types of substance users scored high on factor L (suspicious), F (happy go lucky).

HOW TO CITE THIS ARTICLE: Poonam B, Karun B, Angad SH, et al. Assessment of personality factors among patients presenting with different substance use disorders. J. Evolution Med. Dent. Sci. 2019;8(20):1656-1661, DOI: 10.14260/jemds/2019/366

\section{BACKGROUND}

Personality is deeply ingrained and enduring behavior patterns, inflexible responses to a broad range of personal and social situations. It is persons own self representation emerged from interaction between genetic, environmental and psychosocial factors. Each individual has specific personality traits through which an individual tune with the daily life situations. It is own pattern of thoughts and behavior which makes an individual distinct and unique. All personality traits collectively formulate one's own personality.

Personality disorder tends to appear in late childhood and adolescence and continues to manifest into adulthood. It is therefore unlikely that the diagnosis of personality disorder will be appropriate, before the age of 16 or 17 years.

'Financial or Other Competing Interest': None.

Submission 22-03-2019, Peer Review 01-05-2019,

Acceptance 09-05-2019, Published 20-05-2019.

Corresponding Author:

Dr. Karun Bhatti,

Associate Professor

Department of Medicine,

MMIMSR, Mullana, Ambala, Haryana, India.

E-mail:drkarunbhatti@yahoo.com

DOI: $10.14260 /$ jemds $/ 2019 / 366$

\section{(c) $(7)(-)$}

They are not secondary to another secondary mental disorder or brain disease. Sometimes personality change is acquired in adult life, following severe or prolonged stress, extreme environmental deprivation, serious psychiatric disorder or brain injury or damage. When an individual fails to deal effectively with the life situations and deviates from their normative social norms is labeled as maladaptive behavior. This long-standing maladaptive behavior is labeled as personality disorder. Various personality traits cluster together to form personality. It's not that all personality traits are abnormal but few traits when present in excess can lead to maladaptive behavior. Such personality traits hamper person's cognition, and emotional response towards the life, associated with considerable personal and social disruption.

Substance use disorder is a serious concern for today's life which is increasing on an alarming rate in the whole world. Day by day we are coming across so many individuals who start with the habit of taking substances due to one reason or another in their adolescent age. Usually beginners in adolescent age starts with occasional intake of alcohol, tobacco chewing or nicotine smoking but gradually get dependent on these substances and it became the gate way for the rest including cannabis (Hashish, marijuana), opioids (Heroin, smack), stimulants, LSD, cocaine etc. There are many factors because of which a person starts abusing various substances. Among which the reason can be peer pressure, 
curiosity, poor impulse control, low self-esteem, poor stress management, escape from reality, childhood trauma, relief from fatigue, modeling, easy availability of substances, rapid urbanization, inter familial conflicts, poor social support, to get a new experience, to relax and enjoy, due to social pressure, due to family history.

As there are various personality traits which makes an individual inclined towards substance taking behavior. Substance use disorder is multi rooted disorder where specific genetic makeover, acting vulnerable as predisposing factor along with individual personality traits can be perpetuating factor with accompanying environmental factors acting as a precipitating factor. Thus, personality factors play an important determining role in substance use disorder.[1] The research showed that an individual characteristic plays a dominant role in drug abuse more than the type of substance used for addiction. Even around seven years of age, these traits can be identified in the children's behavior. ${ }^{[2]}$ With reliable measures and proper assessment of the personality traits by psychiatrist as well as by psychologist will surely help to combat the burden of substance use disorders on the patient's overall personality.

\section{Aims and Objectives}

1. To assess any association between the different type of substance use disorder and various socio demographic factors.

2. To assess the scores of different personality factors on 16 PF (Personality factor questionnaire) ${ }^{[3]}$ among different substance use disorders.

\section{METHODS}

It is a hospital based, observational study.

\section{Inclusion Criteria}

Participants, both male and female, aged 18 years and above who gave consent and fulfilling the criteria of substance dependence according to International Classification of Disease -10 were included in the study.

\section{Exclusion Criteria}

- Patients had independent personality disorder prior to the substance use disorder.

- Patient had any other co morbid psychiatric disorder.

\section{Sample Size}

Most of the studies predicting the assessment scores between the personality factors among substance use disorders have shown their co relation coefficient of 0.5 , using which 90 patients were included between a particular period in this study.

\section{Sampling}

This study was conducted on consecutive 90 patients, using convenient sampling, of either gender, presenting in MMIMSR, Mullana (Ambala) a multispecialty teaching hospital in North India, on substance use disorder patients coming in psychiatry and medicine OPD, IPD and various referral patients from other departments of the hospital.

\section{Methodology}

Patients were taken up in three different groups. Each comprising of 30 subjects, in group 1 alcohol dependent patients, group 2 will include opioids dependent patients and group 3 will include other substances (Cannabis, tobacco chewing, nicotine smoking, benzodiazepines etc.)

The patient was diagnosed as a case of substance dependent disorder according to ICD 10 criteria and assessed further using socio demographic proforma and sixteen personality factor questionnaires (16 PF).[3]

The sixteen-personality factor questionnaire (16 PF): Personality assessment was done through the standard scale - 16 P F questionnaire. This is a score based Objective test used to cover all the personality factors possible in the short time. Form E is specially designed for use in the subjects with low level of educational and cultural beliefs. Eight items are provided for each of 16 factors, making 128 items in form E. The questionnaire is framed and planned in a manner to give a maximum scoring accessibility and to cover variety and interest for the evaluator. The test is designed for use with individuals aged 16 and above. There are five forms of $16 \mathrm{PF}$ available. (A, B, C, D, E). Form E is designed for individuals with marked educational and reading deficits. As considering the patient sample more from rural background so form 16 PF (E) was chosen to be used in this current study. 16 dimensions are essentially independent and psychological meaningful.

\section{Statistical Methods}

Results were expressed in frequencies, percentages and appropriate statistical methods (Kruskal-Wallis test and Chi Square test) using Excel was applied accordingly to compute the results of this study material. The participants were told about the nature of the study in detail and informed consent was taken in written form from all the patients. Privacy regarding the subject information was maintained.

\section{RESULTS}

A total of 90 subjects were included in this study.

Table 1 shows the age range of the patient with substance use disorder is $(37.34 \pm 12.68)$ i.e. 20 years to 80 years. There were 90 subjects i.e. 87 (96.7\%) were males and 3 (3.3\%) were females in the study. Out of 90 participants, majority were 62 (68.9\%) were Hindu, second highest Muslim 17 (18.9\%), $9(10.0 \%)$ were Sikh and 2 (2.2\%) belong to others. Among 90 participants 71 (78.9\%) were married and 19 (21.1\%) were unmarried. Education qualification distribution highlights that maximum number of participants were up to high school making it $55(61.1 \%)$, above high school 17 (18.9\%) and $18(20.0 \%)$ were illiterate. Majority of the subjects were semi-skilled 37 (41.1\%), 25 (27.8\%) were skilled and 28 (31.1\%) were unemployed. The distribution frequency according to the locality was 49 (54.4\%) belonging to urban and $41(45.6 \%)$ to rural background.

Table 2 shows the relationship between various demographic data with the various types of substance. No parameter on socio demographic profile was found significantly associated with the type of abuse of any substance in this study. It was observed from the study results that the type of substance abused by the subject was not affected by any socio demographic profile of the subjects. The mean duration of intake of various substances was 
significantly associated with the type of substance abused by the subjects in this study. The mean value of alcoholics and others were $11.27 \pm 8.83$ and $11.27 \pm 8.39$ whereas the mean value for opioids $5.30 \pm 5.025$. The mean value for the opioids was significantly low as compared to alcohol and others.

Range of duration of intake is also significantly associated with type of substance abuse. The range of duration was more in alcoholics and others than in opioids. The number of the subjects taking alcohol and other substance (Cannabis, smoking, tobacco chewing) for more than ten years of duration were more as compared to opioid intake.

Table 4 shows that the various mean score value of $16 \mathrm{PF}$ factors were calculated with the different type of substances. It was found that alcoholics scored high on factors A, F, L reporting that personality traits among these subjects are warm hearted, easy going, participating, enthusiastic, happy go lucky as well as affectogthmia but having suspicious traits too. Alcoholics scored low on factors I and M. They are tough minded, self-reliant, realistic, practical and down to earth. The personality factor scored were high among opioids use disorder on factors $\mathrm{A}, \mathrm{F}, \mathrm{H}$ and $\mathrm{N}$ suggesting that they are outgoing, warm hearted, easy going, participating with enthusiastic traits, venturesome, uninhibited, socially bold, polished and socially aware, shrewdness. Opioids rated low on factors $B, Q_{2}, Q_{4}$. They are less intelligent with concrete thinking, lower scholastic mental capacity, more of group dependent, adjoined and sound follower with group adherence qualities, relaxed, tranquil, not frustrated, composed, more of ergic tension. On factors $F, L, Q_{3}, Q_{4}$, others (Cannabis intake, nicotine smoking, tobacco chewer etc. ) scored higher, depicting that enthusiastic surgency, suspicious, hard to fool, controlled, exacting will power, socially precise, compulsive, high strength on self-sentiments, even tense frustrated, drived, high ergic tension. Only selfdiscipline mean scores were significantly associated with the type of substance abuse participants were using.

Seen in our study among the subjects using other substances (Cannabis, nicotine smoking, tobacco chewers etc.) rated high score on factor L (Suspicious) and low on score on factor B. As the results were in concordance with the cohort study conducted by Lipman et.al.[7] on 55 drug abuse male subjects guilty of murder, upon them 16 PF was administered. Results showed that stimulant abusers positively co related on factor $\mathrm{L}$ and $\mathrm{O}$, negatively on factor Q3 and Q2. Mohamed et.al.[8] studied consecutive 60 male subjects which were divided into two groups. Group 1 included 30 opioids dependent patients and group 2 enrolled 30 as non-substance dependent male patients, to compare the personality profile among both the groups. Subjects from group one was assessed on the addiction severity index. As socio demographic factors of both the group was compared and it was found in group 1, $80 \%$ of the subjects were not working and $66.7 \%$ subjects were divorced whereas in group $2,10 \%$ of the subjects were not working and only one was divorced. As regards the personality test among the group 1, $73.3 \%$ had severe degree of sociopathic traits. So, it was observed that in early onset of drug addiction in childhood and adolescent, impulsive and aggressive personality traits pose great impact. Results in our research showed that opioids user scored low on factor Q3 (Undisciplined selfconflicts) as compared to the subjects in others group and among alcoholics indicating that they have impulsive urges, follow own urges, careless of social rules. They have low integration of self. Even in our research work it was seen that all types of substance user including alcoholics, opioids, and other substance user scored high on factor $\mathrm{F}$ indicating that tend to be cheerful, active, talkative, frank, expressive, and carefree. They are frequently chosen as elected leaders. They may be impulsive and mercurial. A case control study took by Kornor et.al.[9] on 65 opioid dependent patients who were taken after buprenorphine replacement therapy for 5 weeks and on controls with similar socio demographic profile. The personality traits assessment was done using five factor module revised NEO personality inventory (240 items selfreport questionnaire). Results found were that neuroticism score was high and extraversion and conscientiousness score low in cases than the control suggesting that there is difference in personality traits of patients with opioid dependence than from those taken from non-substance dependent subjects. So, results in our study showed that factor Q4 (Tense) was high among other substance user (Cannabis intake, nicotine smoking, tobacco chewer) as compared with alcoholics and opioids indicating frustrated, drived, tense, with high ergic tension. But factor $\mathrm{H}$ (Boldness) was high among opioids user than in alcoholics and other substance user. But these results were contrary with the results shown in the study conducted by Kornor. Devi K S et. al[10] conducted the study on 60 subjects, 30 for control group (Normal group) and 30 for case group (Marijuana users) in the age ranged from 18 to 40 years. To determine the personality changes of marijuana users. All the study subjects are male. General Health Questionnaire (GHQ) 13, 16 PF Questionnaires 14 and Eysenck Personality Questionnaire was used in this study. This result demonstrated that the normal individual and marijuana user group differed significantly on factors $\mathrm{E} \& \mathrm{M}$. The user tends to accommodate others wishes, and are cooperative and agreeable, willing to set aside their own wishes and feelings. The users are more oriented to abstract ideas than the external facts practicalities. Being focused on thinking, imagination and fantasy, high scorers generate many ideas and theories and often creative. Extreme scorers can be so absorbed in thought that they can be absentminded and impractical. But these finding are not found in my current research work. As subjects using other substances (Cannabis, nicotine smoking, tobacco chewer) other than alcohol or opioids scored high on factors L, F, O, Q3.

Among enrolled subjects in our study showed that alcoholics scored high on factors L,F,A and low on factors M, I. Reporting to be impulsive, talkative, frank, expressive, care free tends to get involved into substance taking behavior. Whereas Opioids user scored high on factors $\mathrm{L}, \mathrm{H}$ and $\mathrm{F}$ and low on B, Q 4, Q 2. Tends to be outgoing, soft hearted, socially impressive, cheerful, impulsive, bold, spontaneous and abundant in emotional response. They are more relaxed, composed and satisfied. Sometimes their over satisfaction leads to laziness and low performance. Subjects taking other substances scored high on factors L, F and Q3 and low on factor B. As their evaluation reported that they have tendencies to cheerful, talkative, mistrusting, and doubtful, 
having strong control over their emotions and general behavior.

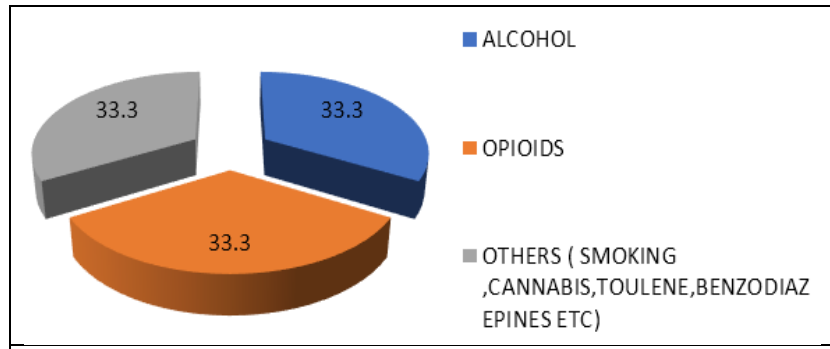

Figure 1. Percentage of each Type of Substance Abuse

\begin{tabular}{|c|c|c|c|c|c|}
\hline \multirow{2}{*}{ Age } & & & & & \\
\cline { 2 - 6 } & N & Minimum & Maximum & Mean & $\begin{array}{c}\text { Std. } \\
\text { Deviation }\end{array}$ \\
\hline $\begin{array}{c}\text { (in } \\
\text { years) }\end{array}$ & 90 & 20 & 80 & 37.34 & 12.612 \\
\hline \multicolumn{7}{|c|}{ Table 1.1 Age of The Patients } \\
\hline
\end{tabular}

\begin{tabular}{|c|c|c|c|}
\hline Character & Category & Number & Percentage \\
\hline \multirow{3}{*}{ Gender } & Female & 3 & 3.3 \\
\hline & Male & 87 & 96.7 \\
\hline & Total & 90 & 100 \\
\hline \multirow{5}{*}{ Religion } & Muslim & 17 & 18.9 \\
\hline & Hindu & 62 & 68.9 \\
\hline & Sikh & 9 & 10 \\
\hline & Others & 2 & 2.2 \\
\hline & Total & 90 & 100 \\
\hline \multirow{3}{*}{ Marital Status } & Unmarried & 19 & 21.1 \\
\hline & Married & 71 & 78.9 \\
\hline & Total & 90 & 100 \\
\hline \multirow{4}{*}{ Education } & Uneducated & 18 & 20 \\
\hline & Up to high school & 55 & 61.1 \\
\hline & Above high school & 17 & 18.9 \\
\hline & \begin{tabular}{|l|} 
Total \\
\end{tabular} & 90 & 100 \\
\hline \multirow{4}{*}{ Occupation } & Unemployed & 28 & 31.1 \\
\hline & Semi-skilled & 37 & 41.1 \\
\hline & Skilled & 25 & 27.8 \\
\hline & Total & 90 & 100 \\
\hline \multirow{3}{*}{$\begin{array}{c}\text { Locality Rural } \\
\text { or Urban }\end{array}$} & Rural & 41 & 45.6 \\
\hline & Urban & 49 & 54.4 \\
\hline & Total & 90 & 100 \\
\hline
\end{tabular}

\begin{tabular}{|c|c|c|c|c|c|}
\hline & \multicolumn{3}{|c|}{ Type of Substance } & \multirow[b]{2}{*}{ value } \\
\hline & & Alcohol & Opioids & $\begin{array}{c}\text { Others } \\
\text { (Smoking, } \\
\text { Cannabis, } \\
\text { Toluene, Benzo- } \\
\text { diazepines Etc.) }\end{array}$ & \\
\hline \multirow{2}{*}{ Sex } & Female & $0(0.00 \%)$ & $2(2.20 \%)$ & $1(1.10 \%)$ & \multirow[b]{2}{*}{0.35} \\
\hline & Male & $30(33.3 \%)$ & $28(31.1 \%)$ & $29(32.2 \%)$ & \\
\hline \multirow{4}{*}{ Religion } & Muslim & $3(3.3 \%)$ & $5(5.6 \%)$ & $9(10 \%)$ & \multirow{4}{*}{0.05} \\
\hline & Hindu & $23(25.6 \%)$ & $18(20 \%)$ & $21(23.3 \%)$ & \\
\hline & Sikh & $4(4.4 \%)$ & $5(5.6 \%)$ & $0(0 \%)$ & \\
\hline & Others & $0(0 \%)$ & $2(2.2 \%)$ & $0(0 \%)$ & \\
\hline \multirow{3}{*}{$\begin{array}{l}\text { Marital } \\
\text { Status }\end{array}$} & Unmarried & $5(5.6 \%)$ & $9(10 \%)$ & $5(5.6 \%)$ & \multirow{2}{*}{0.344} \\
\hline & Married & $25(27.8 \%)$ & $21(23.3 \%)$ & $25(27.8 \%)$ & \\
\hline & Uneducated & $6(6.7 \%)$ & $9(10 \%)$ & $3(3.3 \%)$ & \multirow{3}{*}{0.316} \\
\hline \multirow{2}{*}{$\begin{array}{c}\text { Educati } \\
\text { on }\end{array}$} & $\begin{array}{l}\text { Up to high } \\
\text { School }\end{array}$ & $20(22.2 \%)$ & $15(16.7 \%)$ & $20(22.2 \%)$ & \\
\hline & $\begin{array}{l}\text { High school } \\
\text { and above }\end{array}$ & $4(4.4 \%)$ & $6(6.7 \%)$ & $7(7.8 \%)$ & \\
\hline \multirow{2}{*}{$\begin{array}{c}\text { Occupati } \\
\text { on }\end{array}$} & Unemployed & $10(11.1 \%)$ & $11(12.2 \%)$ & $7(7.8 \%)$ & \multirow[b]{2}{*}{0.067} \\
\hline & Semi-skilled & $13(14.4 \%)$ & $15(16.7 \%)$ & $9(10 \%)$ & \\
\hline
\end{tabular}

\begin{tabular}{|c|c|c|c|c|c|}
\hline & Skilled & $7(7.8 \%)$ & $4(4.4 \%)$ & $14(15.6 \%)$ & \\
\cline { 1 - 5 } $\begin{array}{c}\text { Locality } \\
\text { Rural or } \\
\text { Urban }\end{array}$ & Rural & $16(17.8 \%)$ & $15(16.7 \%)$ & $10(11.1 \%)$ & \\
\cline { 2 - 5 } & Urban & $14(15.6 \%)$ & $15(16.7 \%)$ & $20(22.2 \%)$ & \\
\hline \multicolumn{2}{|c|}{ Total } & $\mathbf{3 0 ( 3 3 . 3 \% )}$ & $\mathbf{3 0}(\mathbf{3 3 . 3 \%})$ & $\mathbf{3 0}(\mathbf{3 3 . 3 \% )}$ & \\
\hline
\end{tabular}

Table 2. Association Between Different Substance Use Subjects with Socio-Demographic Data

\begin{tabular}{|c|c|c|c|c|c|c|c|}
\hline & \multicolumn{7}{|c|}{ Duration of Intake } \\
\hline & \multirow[t]{2}{*}{$\mathbf{N}$} & \multirow[t]{2}{*}{ Mean } & \multirow[t]{2}{*}{$\begin{array}{c}\text { Std. } \\
\text { Deviation }\end{array}$} & \multirow[t]{2}{*}{$\begin{array}{l}\text { Std. } \\
\text { Error }\end{array}$} & \multicolumn{2}{|c|}{\begin{tabular}{|c|}
$95 \%$ \\
Confidence \\
Interval for \\
Mean
\end{tabular}} & \multirow[t]{2}{*}{$\begin{array}{c}\mathbf{p} \\
\text { value }\end{array}$} \\
\hline & & & & & $\begin{array}{l}\text { Lower } \\
\text { Bound }\end{array}$ & $\begin{array}{l}\text { Upper } \\
\text { Bound }\end{array}$ & \\
\hline Alcohol & 30 & 11.27 & 8.839 & 1.614 & 7.97 & 14.57 & \multirow{3}{*}{0.003} \\
\hline Opioids & 30 & 5.30 & 5.025 & 0.917 & 3.42 & 7.18 & \\
\hline Others & 30 & 11.27 & 8.399 & 1.533 & 8.13 & 14.40 & \\
\hline Total & 90 & 9.28 & 8.042 & 848 & 7.59 & 10.96 & \\
\hline
\end{tabular}

Table 3. Relationship Between the Type (Alcohol, Opioids, others Smoking, Cannabis, Toluene, Benzodiazepines etc.) of The Substances and Duration of Intake of these Substances

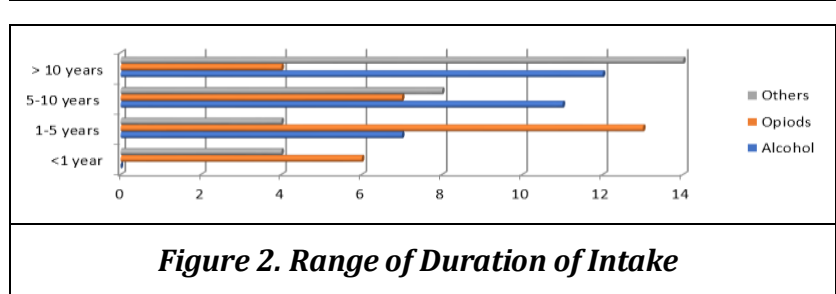

\begin{tabular}{|c|c|c|c|c|}
\hline & & Mean & $\begin{array}{c}\text { Std. } \\
\text { Deviation }\end{array}$ & p Value \\
\hline \multirow{3}{*}{ Warmth } & Alcohol & 5.73 & 1.929 & \multirow{3}{*}{0.680} \\
\hline & Opioids & 5.30 & 1.725 & \\
\hline & Others & 5.43 & 2.176 & \\
\hline \multirow{3}{*}{ Intelligence } & Alcohol & 4.87 & 2.145 & \multirow{3}{*}{0.211} \\
\hline & Opioids & 4.13 & 1.525 & \\
\hline & Others & 4.77 & 1.431 & \\
\hline \multirow{3}{*}{$\begin{array}{c}\text { Emotional } \\
\text { Stability }\end{array}$} & Alcohol & 4.97 & 2.157 & \multirow{3}{*}{0.859} \\
\hline & Opioids & 4.80 & 1.808 & \\
\hline & Others & 5.07 & 1.680 & \\
\hline \multirow{3}{*}{ Dominance } & Alcohol & 5.10 & 1.826 & \multirow{3}{*}{0.964} \\
\hline & Opioids & 4.97 & 2.092 & \\
\hline & Others & 5.03 & 1.810 & \\
\hline \multirow{3}{*}{ Impulsivity } & Alcohol & 5.63 & 1.956 & \multirow{3}{*}{0.931} \\
\hline & Opioids & 5.63 & 2.157 & \\
\hline & Others & 5.80 & 1.789 & \\
\hline \multirow{3}{*}{ Conformity } & Alcohol & 5.10 & 1.398 & \multirow{3}{*}{0.135} \\
\hline & Opioids & 5.07 & 2.348 & \\
\hline & Others & 5.90 & 1.517 & \\
\hline \multirow{3}{*}{ Boldness } & Alcohol & 5.37 & 1.938 & \multirow{3}{*}{0.477} \\
\hline & Opioids & 5.90 & 1.470 & \\
\hline & Others & 5.43 & 2.063 & \\
\hline \multirow{3}{*}{ Sensitivity } & Alcohol & 4.47 & 1.907 & \multirow{3}{*}{0.203} \\
\hline & Opioids & 4.93 & 1.999 & \\
\hline & Others & 5.33 & 1.668 & \\
\hline \multirow{3}{*}{$\begin{array}{c}\text { Suspi } \\
\text { ciousness }\end{array}$} & Alcohol & 5.67 & 1.709 & \multirow{3}{*}{0.696} \\
\hline & Opioids & 5.50 & 2.047 & \\
\hline & Others & 5.93 & 2.164 & \\
\hline \multirow{4}{*}{ Imagination } & Alcohol & 4.37 & 1.691 & \multirow{3}{*}{0.215} \\
\hline & Opioids & 5.13 & 2.374 & \\
\hline & Others & 5.20 & 1.955 & \\
\hline & Alcohol & 4.87 & 1.776 & 0.321 \\
\hline
\end{tabular}




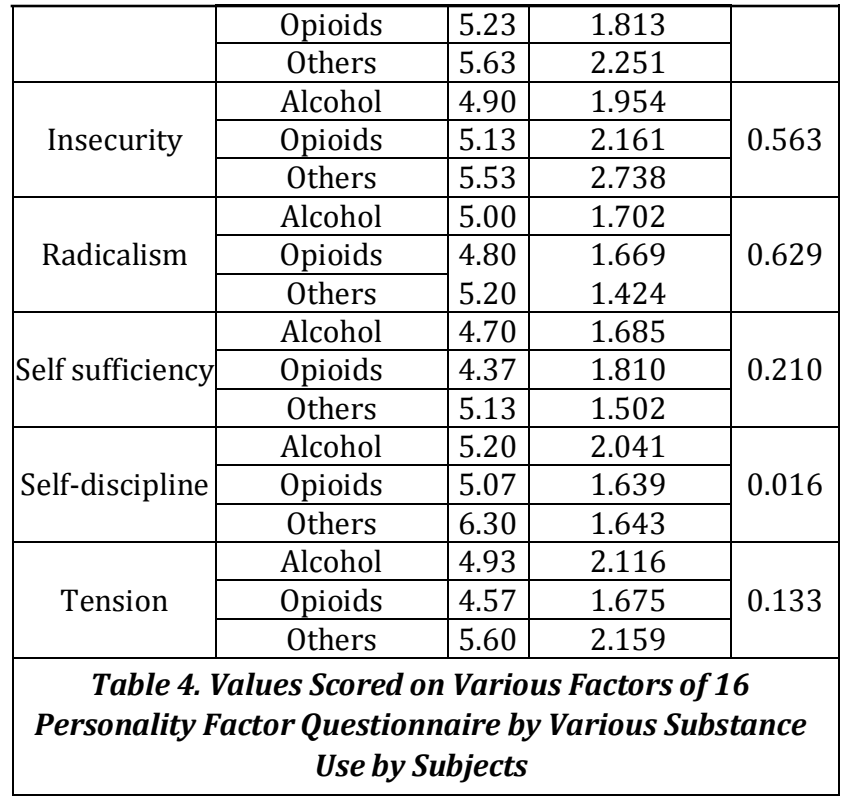

\section{DISCUSSION}

No one is inclined towards substance use disorder; certain personality factors pose greater risk towards substance use disorder. Enumerating few of the traits among those fighting with the substance use disorder. Among which compulsive urge (Instant gratification), impulsivity found to be most common traits among the substance user. Just going out with a friend for a single drink, sooner or later turns to multiple. Sometimes due to hard times in the life or because of depressive symptoms (Feeling of inadequacy), anxiety symptoms (Shyness, social phobia), one gets into substance taking behavior to combat with these feelings. Anti-social personality traits have higher tendencies towards substance use disorders. In our study, results showed that the alcoholics and subjects enrolled in others group scored high mean on factor $\mathrm{L}$ (suspicious) indicating to be mistrusting and doubtful, often involved in their own egos and are selfopinionated. Usually they are deliberate in their actions with poor team members. Similar results were found in the study conducted by Roy et. al.[4] where case controlled cross sectional study on 250 cases of substance use disorder and same number of control with similar socio demographic profile was taken up. The personality traits were measured using Eysenck personality questionnaire. Results showed that neuroticism and psychoticism were remarkably higher in cases than control. Psychoticism was the prevalent trait in the substance use disorders in Bangladesh. But low mean score on factor Q4 (tense) were seen among opioids user in our study reflecting that opioid users tend to be relaxed, composed and satisfied, (Not frustrated). But this finding was found to be contradicting with the results seen in the study conducted by Roy et al.[4] The possible explanation might be people start taking opioids to overcome their anxiety issues, after that they start taking opioids to combat with their anxiety symptoms and to feel more relaxed and composed. Echeburuaet.al.[5] took up study on 91 subjects, out of which 30 were consecutively recruited alcohol dependent patients, 30 psychiatry patients suffering from non-substance dependent disorders and remaining 31 controls from normative population with similar socio-demographic profile, assessed their personality traits on IPDE and million clinical multiaxial inventory 2 . Results showed at least one personality disorder in $40 \%$ of alcohol dependent patients, in $16.6 \%$ of general psychiatry patients and in $6.4 \%$ from general sample. Among personality disorders, dependent personality disorder was most prevalent $(13.3 \%)$ and $10 \%$ each were paranoid and obsessive-compulsive personality disorder. In our study similar results of dependent type of personality traits were seen in opioids, as their mean score value was low on factor Q2 (Group dependent), Individuals scoring low on factor Q2 prefer to work and make decisions with other people and like to depend on social approval and admiration. They tend to go along with the group and may be lacking in individual resolution. They are not necessarily gregarious by choice rather they might need group support. Even alcoholics and others scored high mean value on factor L (Suspicious), indicating their doubtful and mistrusting nature, showing paranoid traits in them. The finding in our study were well supported with the above study results. In our research study, sensational seeking traits were seen among opioids user as they scored high on factor $\mathrm{H}$ (Bold, Venturesome) and F (Happy go lucky). Subjects scoring high on factor $\mathrm{H}$ are sociable, bold, ready to try new things, spontaneous and abundant in emotional response. Their thick-skinnedness enable them to face wear and tear in dealing with people and growling emotional situations without fatigue. one who scored high on Factor $\mathrm{F}$ tends to be cheerful, active, talkative, frank, expressive, effervescent and care free. They are frequently chosen as elective leaders. Depicting sensational seeking traits. Our results were well supported with the findings found in the cross-sectional study done by Jallian et.al.[6] in Iran on randomly selected 425 male medical students of substance use disorder, including smoking, psychoactive drug abuse and alcohol drinking to assess the role of personality factors among them. Results showed that sensational seeking was the best predictor factor among the cigarette smoking, alcohol drinking and psychotropic drug use.

\section{CONCLUSIONS}

Substance dependence becomes a major issue if not handled properly by the professional healers, as biopsychosocial model and various personality factors play major role in person's behavior. Enrolled subjects taken up on $16 \mathrm{PF}$ personality test were divided in three groups. It was observed that all type of substance users scored high on factor L (suspicious), F (happy go lucky). So, if proper assessment of the subject's personality traits is done, that can act as a guide to assess potential risk factors for substance use disorder. The early one gets help, the better will be the long-term success. Above findings will help in understanding the personality factors of subjects taking different types of substances. With proper treatment strategies and personality assessment, the burden of substance use dependence can be dropped down drastically. So proper measures can be taken before the person gets drowned in the substance taking behaviour.

\section{REFERENCES}

[1] Galanter M, Kleber HD. Textbook of substance abuse treatment. $2^{\text {nd }}$ edn. The American Psychiatric Press 1999: p. 53-4. 
[2] Shedler J, Block J. Adolescent drug use and psychological health. A longitudinal inquiry. Am Psychol 1990;45(5):612-30.

[3] Cattell RB, Eber HW, Tatsuoka MM. Handbook for the sixteen personality factor questionnaire (16 PF): In clinical, educational, industrial, and research psychology, for use with all forms of the test. Institute for Personality and Ability Testing: 1970 .

[4] Roy J, Morshed NM, Qusar S, et al. Personality traits of substance users in Bangladesh. BSMMU J 2010;3(2):76-81.

[5] Echeburúa E, de Medina RB, Aizpiri J. Alcoholism and personality disorders: an exploratory study. Alcohol Alcohol 2005;40(4):323-6.

[6] Jalilian F, Matin BK, Ahmadpanah M, et al. The personality factors predictors in substance abuse among Iranian college students. International Journal of High Risk Behaviors and Addiction 2017;6(1):e27551.

[7] Lipman JJ. Personality, drug abuse and murder: a pilot study. The Forensic Examiner 2001;10(1-2)1-7.

[8] Mohamed S. Assessment of personality traits in a sample of opioid-dependent patients in comparison with nondependent men. Egyptian Journal of Psychiatry 2017;38(1):19-26.

[9] Kornør H, Nordvik H. Five-factor model personality traits in opioid dependence. BMC Psychiatry 2007;7:37.

[10] Devi KS, Devraj L. A study of personality profiles of marijuana users. Journal of Medical Science and Clinical Research 2018;6(7):458-62. 